\title{
Long-Term Durability of Dental Adhesives
}

\author{
A. Tezvergil-Mutluay ${ }^{1,2} \cdot$ D. Pashley ${ }^{3} \cdot$ M. M. Mutluay ${ }^{1}$
}

Published online: 5 October 2015

(C) Springer International Publishing AG 2015

\begin{abstract}
The use of tooth-colored dental restorative materials, along with the adhesive techniques, has become routine in today's dental practice. The longevity of adhesive restorations depends mainly on good bonding between restorative materials and tooth structure, which should be achieved in situ, within minutes. While bonding to enamel is reliable through micromechanical retention, bonding to dentin presents challenges due to its more complex collagenous structure. Progressive loss of resin-dentin bond integrity and reduction in bond strength have been extensively reported. This was attributed partly to the hydrophilic nature of the contemporary adhesives systems that causes unwanted water absorption, phase separation, and resin leaching and also to the endogenous collagenolytic enzymes that can slowly hydrolyze collagen. Current research in this field aims at increasing the durability of resin-dentin bonds by inhibition of the collagenolytic activity of dentin, as well as implementing bonding strategies which allow the use of more hydrophobic bonding agents.
\end{abstract}

Keywords Adhesives · Bond strength · Dentin · Collagen · Durability $\cdot$ Cross-linker $\cdot$ Matrix metalloproteinase $\cdot$ Cycteine cathepsins

This article is part of the Topical Collection on Dental Restorative Materials

A. Tezvergil-Mutluay

arztez@utu.fi

1 Department of Restorative Dentistry and Cariology, Adhesive Dentistry Research Group, Institute of Dentistry, University of Turku, Lemminkaisenkatu 2, FI-20520 Turku, Finland

2 Turku University Hospital, TYKS, University of Turku, Turku, Finland

3 School of Dentistry, Georgia Regents University, Augusta, GA, USA

\section{Introduction}

As we celebrate the 60th year of adhesive dentistry, continuing advances in bonding technology have made a large impact in daily clinical practice. With improvements in adhesive technology, minimally invasive, tooth-colored, adhesive restorations have replaced conventional restorations that sacrificed sound tooth structure for extra retention [1]. The use of toothcolored restorations are expected to increase due to increased esthetic demands, the feared toxicity of mercury-containing dental amalgam, and legislation restricting the manufacture and disposal of mercury-containing materials [2]. The ultimate goal of adhesive procedures is to achieve a good longlasting seal between the restoration and tooth structure, through surface modification and micromechanical retention [3]. However, despite improvements in adhesive techniques, data from a large cross-sectional cohort of patients $(80,000$ from UK General Dental Service, 2001) demonstrated that resin-based tooth-colored restorations placed in non-loadbearing cavities $(127,375)$ had a functional life of only $43 \%$ after 10 years [4]. Similarly, in the USA, the National Institute of Dental and Craniofacial Research (NIDCR) reported that the longevity of tooth-colored restorations is only 5.7 years and that $60 \%$ of total restorative treatment is replacement of degrading existing fillings [5]. This replacement dentistry has an annual cost of $\$ 4-5$ billion in the USA alone [6, 7]. The reason for replacements of tooth-colored restorations is generally due to failure of resin-dentin bonds that results in marginal gap formation and development of secondary caries, and subsequent loss of the restoration $[8,9]$.

Therefore, the objectives of this review are to summarize the current knowledge on the factors affecting the long-term durability of dental adhesives and examine new techniques designed to improve the long-term durability of adhesive interfaces, by improving the physicochemical properties of the 
contemporary adhesives, and to block the aging mechanisms involved in the degradation of adhesive interfaces, as well as new therapeutic approaches to prevent and counteract this degradation.

\section{Factors Affecting the Durability of Dental Adhesives}

\section{Enamel and Dentin as Bonding Substrates}

The tooth is a remarkable example of a natural composite. Stiff, hard, brittle enamel on the outside of the teeth provides wear and acid resistance, whereas the softer, flexible underlying tough dentin is able to absorb chewing stresses without fracturing [10]. Although these two natural composites serve successfully in the oral cavity, when replacement is needed, reliable attachment of restorative materials to enamel and dentin is difficult to achieve due to the large differences between enamel and dentin structure. For instance, enamel is composed of $90 \mathrm{vol} \%$ mineral, $4 \%$ protein, and $6 \%$ water. That high mineral content, without any modification, lacks sufficient roughness to allow for tooth-colored restorations to adhere to enamel [11].

In 1955, Buonocore introduced a surface modification technique for enamel using $85 \%$ phosphoric acid to acidetch the enamel surface for $30 \mathrm{~s}$ [12]. That technique has been modified to reduce the acid concentrations to $32-37 \%$, as well as etching time to $15 \mathrm{~s}[13,14]$, and successfully used since then. On enamel, acid etching cleans the surface by removing organic pellicle on the surface, and by removing cutting debris called "the smear layer" on cut enamel, and also partially dissolves the enamel rods, creating millions of microporosities for inter- and intra-crystallite bonding sites for liquid resin [15]. After polymerization, millions of micromechanically interlocked solid resin tags provide a stable resin-enamel bonding interface. The very low protein and water as well as the presence of high mineral content ( $96 \%$ hydroxyapatite by weight) in enamel are the key for reliable adhesion of resin to enamel microporosities $[11,16]$. This reliable surface bonding is responsible for these minimally invasive restorations lasting more than 20 years [17] as well as protecting the dentin bond against bacterial invasion [18].

Stable adhesion to dentin, on the other hand, has been very difficult to achieve. Dentin contains only $50 \mathrm{vol} \%$ of mineral, and the rest is organic matrix (30\%) mainly composed of type I collagen (90\%) and non-collagenous proteins (10\%) with the remaining $20 \%$ being composed of water [11, 19]. During the acid etching phase of the bonding, where both enamel and dentin are simultaneously etched, the entire mineral content of dentin is solubilized and replaced by water, increasing the water content up to $70 \%$ [20]. To obtain adhesion of resins to dentin, the liquid mixture of solvents and adhesive monomers attempts to displace all that water within $1-2 \mathrm{~min}$. This is then followed by light curing that turns the liquid monomer into solid tooth-colored polymerized plastic resin. This plastic-reinforced collagen fibril is called the "hybrid layer" [21], in which the collagen fibrils of the completely demineralized dentin matrix anchor the overlying adhesive resin and tooth-colored resin composites to the underlying mineralized dentin. Pashley et al. [20] defined resin bonding as a unique form of in situ tissue engineering, involving a series of modifications to dentin and enamel, thereby changing its physicochemical properties from its original hydrophilic, crystalline impermeable structure, to a permeable matrix that becomes a tougher and acid-resistant material [22]. Proper resin adhesion by encapsulation of collagen fibrils with adhesive resins leads to longer-lasting restorations, reduced destruction of dental tissues, and reduced tooth sensitivity. Despite the advent of the contemporary dental adhesives that contain hydrophilic resin monomers to enhance resin coupling to wet dentin, resin-dentin bonds are still imperfect and less durable than resin-enamel bonds over time [20, 23-25]. Although the dentin bonds have high immediate bond strengths, they lose about $50-60 \%$ of their strength after 12 years of aging both in vitro [23] and in vivo [25, 26]. Both the complexity of the dentin structure, including significant amount of organic material (type I collagen) $[19,20]$, and excess amounts of residual water [18], as well as the hydrophilic nature of the adhesives which increases water sorption [27], are the major challenges for dentin bonding.

Cavity preparation results in the formation of a loosely attached 1-2- $\mu$ m-thick layer of cutting debris, called the "smear layer," on the tooth surface [28]. Smear layers constitute an unstable barrier to adhesives and cannot be blown or rinsed off easily. The smear layer can be removed by acid etching, or it can be modified by acidic adhesives that can penetrate through the smear layer in order to produce more stable bonding [29].

\section{Etch and Rinse Versus Self-Etch Adhesives}

Etch-and-rinse adhesive systems are the most commonly used adhesive systems for bonding. The technique involves either three steps: a separate application of an acidic etchant, application of separate primers and adhesives, or two steps that include a separate etching step and the use of premixed primer and adhesive in the same bottle. The adhesion strategy involves the removal of the smear layer and superficial hydroxyapatite through $32-37 \%$ phosphoric acid etching for $15 \mathrm{~s}$ to expose the underlying type I collagen fibrils of the dentin matrix [10]. This not only removes the smear layer, but it also removes the mineral phase of the underlying mineral matrix to a depth of 5-8 $\mu \mathrm{m}$. After rinsing away the unreacted acid and the solubilized minerals, the acid-etched matrix contains about 70 vol $\%$ of water between the collagen fibrils [20]. Despite the success of etch-and-rinse adhesive systems for enamel 
bonding [17], the technique sensitivity of dentin bonding [30] and the inconsistency in collagen fibril encapsulation due to the high residual water content [31] through the whole depth of demineralization zone raised questions about durability. Many adhesive monomers are not very soluble in water. This results in hybrid layers that are half-filled with water and the other half-filled with adhesive resin. Hashimoto et al. [23] showed that hybrid layers created with three-step etch-and-rinse adhesive systems showed both loss of resin from intra-fibriller spaces as well as disorganized collagen fibrils after 1 year of water storage, followed by more publications showing similar results [26, 32].

The second adhesive bonding strategy involves the use of self-etching adhesives, which are acidic enough to make the smear layer permeable without completely removing it. Selfetch adhesive systems were developed to reduce the number of application steps in order to create more user-friendly adhesive systems [33]. They are supposed to eliminate the risk of over-etching and over-drying. Self-etch adhesive systems do not require separate acid etching and rinsing steps, since they are composed of aqueous mixtures of acidic monomers (such as phosphoric acid or carboxylic acid esters) that simultaneously etch and infiltrate enamel and dentin [34]. As a result, the dissolved smear layer and demineralization products are not rinsed away but are incorporated into the hybrid layer [34, 35]. The mechanical interlocking is shallower compared to etch-and-rinse adhesives, and additionally some of the adhesive monomers chemically interact with residual hydroxyapatite [35].

In two-step self-etching adhesives, the first step includes application of an acidic hydrophilic primer that etches through the smear layer and into the underlying mineral matrix of about $0.5-1 \mu \mathrm{m}$. Without rinsing, the $25 \%$ water in the primer is evaporated with an air stream. The second step includes a more hydrophobic adhesive resin that is free of solvents. This hydrophobic adhesive resin step makes the interface more hydrophobic and seals the bond very effectively. In one-step (so-called all-in-one) self-adhesive systems, etching, priming, and resin bonding components are all accomplished by several application of a single mixture in one bottle. Water is an essential component of self-etch adhesives as it is needed in the ionization of acidic monomers, but they only use about $25 \%$ water [33], while etch-and-rinse adhesives must deal with $70 \mathrm{vol} \%$ of water [20].

\section{Hydrolytic Degradation of Adhesives}

Ever since John Kanca [36] introduced the wet bonding technique to prevent the collapse of demineralized collagen matrix, manufacturers have had to incorporate increasing concentrations of hydrophilic monomers such as hydroxyethyl methacrylate (HEMA) to serve as a solvent for hydrophobic monomer blends, to enhance the wetting properties [37], to avoid phase changes that occurred when dimethacrylate-based adhesives were applied to water-saturated dentin matrices [38]. Hydrophilic and ionic resin monomers are vulnerable to hydrolysis, due to the presence of ester linkages [27], and increasing the HEMA content of adhesives was shown to increase water sorption into polymerized polymers over time thereby lowering their mechanical properties [39]. However, in addition to hydrophilicity, both organic solvents (ethanol/ acetone) and water retained within the hybrid layer [39, 40] can compromise the integrity of hybrid layer (Fig. 1). A previous investigation showed that acetone- or ethanol-based adhesive mixtures showed an increased solvent retention between 4.9 and $13.2 \%$ with the increased hydrophilicity of adhesive monomer, and the retention increased further to $26.4-41.6 \%$ when water was added to simulate wet bonding conditions [41]. These residual solvents could further compromise the cross-linking reaction during polymerization, affecting the ultimate tensile strength of resin as well as the hybrid layer [42].

The same problem is evident with all-in-one self-etch adhesives. Due to their hydrophilicity, and lack of a separate hydrophobic resin seal, cured adhesive layers may act as permeable membranes [43], permitting water movement across the adhesive layer when applied on wet dentin. Reticular patterns of silver nanoleakeage (so-called "water trees") have been found within the adhesive layer of simplified adhesives [44]. They are considered as sites of incomplete water removal and subsequent suboptimally polymerized resins, which lead to lower bond strength and less durable bonding [43].

A recent systematic review on the failure rates of class $\mathrm{V}$ bonded restorations showed that two-step mild, self-etch, as well as three-step etch-and-rinse restorations with a relatively hydrophobic resin coating layer on top of the hydrophilic primer showed lower failure rates compared to strong all-inone or two-step etch and rinse adhesives [33].

\section{Degradation of Collagen Fibrils}

The very first evidence of collagenolytic activity in carious or intact dentin was reported in the early 1980s [45], and later, Tjäderhane et al. identified matrix metalloproteinases (MMPs) as being responsible for that activity [46]. However, this did not attract much attention in restorative dentistry field, until Armstrong et al. [47] published transmission electron microscopy images of normal versus degraded hybrid layers created with three-step etch-and-rinse adhesive aged for 4 years in vitro. Those images showed the disappearance of resin as well as collagen fibrils from hybrid layers. That same year, Pashley et al. [48] published results demonstrating that human dentin powder contained endogenous proteinases that can degrade the collagen matrix in the absence of bacteria. This opened a new era in understanding the complex degradation processes in adhesive/tooth hybrid layers, and considerable 
Fig. 1 a The 3D schematic showing the denuded collagen filled with water extending to the adhesive layer. b Confocal laser scanning microscopy images of resin-dentin bonds showing resin (black areas) versus water (red) distribution in the hybrid layers. $C$ Composite resin, $A$ adhesive, and $D$ dentin

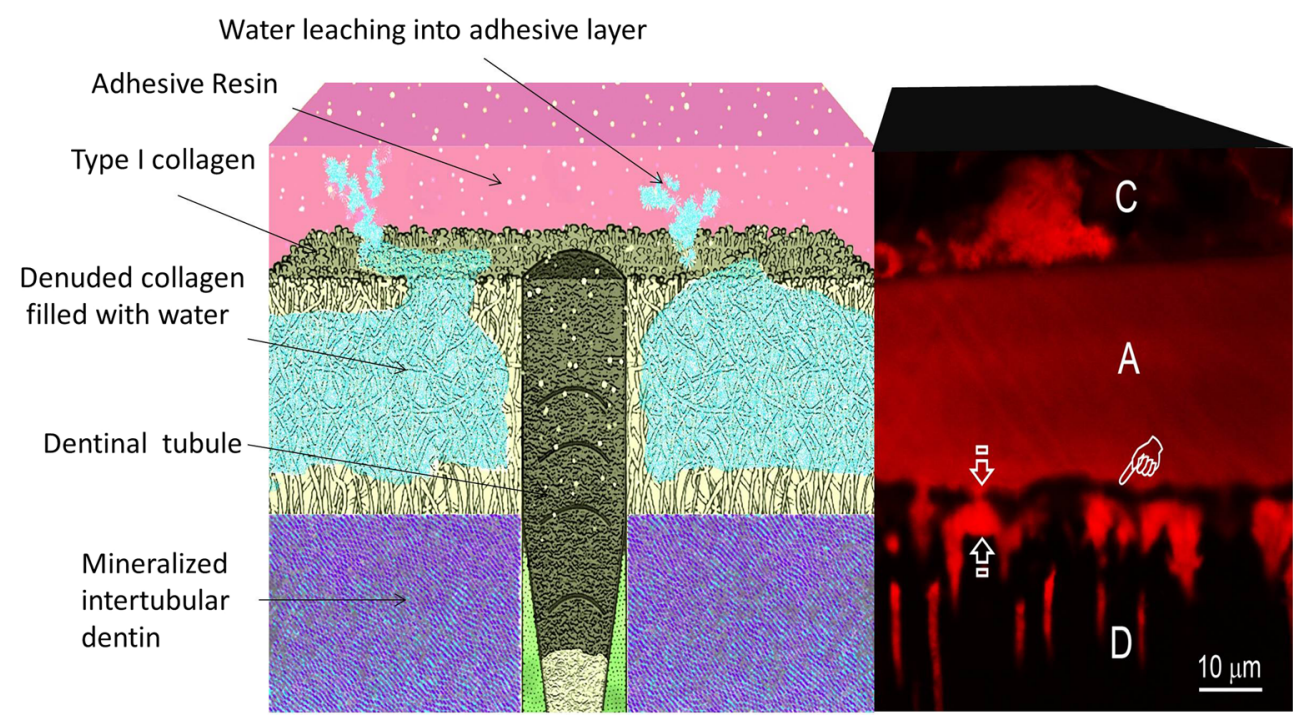

interest has been devoted to understanding the role of these enzymes in resin-dentin bond degradation as well as detection of these proteases in hybrid layers. Using advanced immunolabeling protocols, Breschi et al. [49] showed different degrees of resin-collagen fibril interactions. Mazzoni et al. [50] showed the localization of functional activity of dentin proteases to the bottom of hybrid layers using in situ zymography in hybrid layers created by etch-and- rinse adhesives. Enzyme-induced collagen degradation was shown to lead to a complete loss of the hybrid layer integrity and eventually loss of restorative bond strength [25, 47, 51], and the process is at least as fast in vivo as it is in in vitro conditions. Indeed, hybrid layer degradation occurred in as little as 6 months in primary teeth [25].

\section{Collagenolytic Enzymes in Dental Tissues}

Over the last 10 years, several MMPs and cysteine cathespins have been identified in dentin that takes part in the degradation process. Since the function of MMPs and cathepsins in dentin were presented in detail in several recent review articles [52, 53 , 54], they will only briefly be mentioned in this review. MMPs and cathepsins are two distinct enzymatic families and are expressed by human odontoblasts at the mRNA level [55, 56]. MMPs are a family of zinc- and calcium-dependent endopeptidases which degrade extracellular matrix proteins, including native type I collagen [57]. MMPs are involved in physiological tissue remodeling, but their expression increases dramatically in pathological conditions including dental caries and erosion [58••, 59]. MMPs consist of a prodomain, a catalytic domain with a highly conserved zinc binding site, a hinge region, and a hemopexin domain. The catalytic domain contains cysteine-rich repeats that are necessary for binding and cleaving activities of these proteolytic enzymes. MMP activity can be regulated by autolysis, other MMPs, and tissue inhibitors of metalloproteinases (TIMPs) [57]. The odontoblasts in human teeth synthesize and release several MMPs, including MMP-8 [60] and gelatinases MMP-2 and MMP-9 $[46,61,62]$. Both the latent and active forms of stromelysin MMP-3 [63], collagenase MMP-8 [60, 64], and gelatinases MMP-2 and MMP-9 were identified in demineralized dentin matrices [61, 62]. Secreted as inactive proenzymes (zymogens), MMPs are trapped in the mineralized dentin matrix but became activated in acidic environments [46]. However, they require a neutral $\mathrm{pH}$ to cleave the triple-helical structure at specific site [57]. MMP-2 and MMP-9 were also shown to be telopeptidases that can remove bulky globular telopeptidases from collagen, setting the scene for the true collagenases to access the hydrolytic sites $[65,66]$. Mild self-etch adhesives have been shown to activate MMPs [67]. Additionally, recent studies showed that even in highly acidic conditions, MMP can survive well and that their activity is not decreased by use of $37 \%$ phosphoric acid etching [68].

Cysteine cathepsins (CCs) belong to the $\mathrm{C} 1$ family of papain-like enzymes, most of them (including $\mathrm{CC}-\mathrm{B}$ and $-\mathrm{L}$ ) with ubiquitous expression in human tissues, some (e.g., CC$\mathrm{K}$ and - $\mathrm{L}$ ) being tissue-specific. $\mathrm{CC}-\mathrm{K}$ is the most potent mammalian collagenase, and even though $\mathrm{CCs}$ in general are most active in acidic milieu, CC-B has endopeptidase activity at neutral $\mathrm{pH}[53 \bullet, 56,58 \bullet \bullet$. Some recent reports also showed the positive correlation between the cysteine cathepsin and MMP activities in intact and carious dentin, with caries dentin showing 10 times higher activities than intact dentin, suggesting that these two distinct enzymes could also work together at the degradation of the carious matrices [56, 58・•, 69]. Additionally, several studies quantified the degradation 
products of MMP-mediated (ICTP) and cathepsin-mediated (CTX) C-terminal telopeptide of the collagen [70] suggesting a higher activity of MMPs than cathepsins, and also showing the degradation activity caused by each enzymatic group separately, even in the presence of specific inhibitors used to block the activity of the MMPs and cathepsins [68, 71•].

\section{Strategies to Reduce the Endogenous Enzymatic Activity of Demineralized Dentin Matrices}

The inhibition of these endogenous proteases is another goal in prevention of degradation of dental adhesive bonds. Several different strategies used in in vitro and in vivo experiments with commercially available resin composite systems in human teeth have already demonstrated that the loss of bond strength can be prevented with $2 \%$ chlorhexidine (CHX), a potent anti-microbial agent widely used in dentistry, but also known to inhibit MMPs and cathepsins [25, 48, 72, 73]. Clinically, CHX has been used as a pretreatment step after acid etching and is followed by the application of primer and adhesive resins [53 ${ }^{\circ}$. Close to 20 separate published papers with comparable experimental designs, using $2 \% \mathrm{CHX}$, showed a monthly mean bond strength loss of $5.1 \%$ in untreated control teeth, while CHX-treated teeth only lost $1.9 \%$ [74]. In a clinical study, bond strength reduced only by $1.5 \%$ in 14 months in the CHX-pretreated group, in comparison to $35.2 \%$ in the no-treatment controls [51]. Although low concentrations such as $0.002 \% \mathrm{CHX}$ and shorter applications of $15 \mathrm{~s}$ seem to preserve the resin dentin bond strength over 6 months incubation period [75], most clinicians use $2.0 \%$ CHX for $60 \mathrm{~s}[25,51,53 \bullet, 76,77]$. However, despite the reduced degradation reported in clinical studies $[25,51,53$, $76,77]$, the evidence of CHX inhibition over longer time periods is limited. Additionally, since CHX binding to dentin is largely electrostatic, it can slowly debind and be lost from the hybrid layers [78]. A previous report showed good preservation of hybrid layers after 9 months, but not after 18 months [79], which might be explained by debinding and leaching of water-soluble CHX from adhesive interfaces. To prevent the leaching of CHX from the adhesive interfaces, experimental CHX-methacrylate monomers which can polymerize to resin in the hybrid layers were tested along with its anti-MMP activity that was comparable to CHX [80]. Despite the fact that CHX is the most commonly used anti-MMP agent, its additional bonding step might limit the acceptance by clinicians. The urgent need for user-friendly application methods preferably incorporated into the adhesive systems to inhibit enzymatic degradation is apparent [20,53•].

Other anti-microbial agents such as quaternary ammonium compounds have also shown to be effective MMP inhibitors [71•, 81-83]. Similar to CHX, these compounds are also cationic. Some examples of these compounds include benzalkonium chloride (BAC), an anti-microbial agent, and surfactant, already in clinical use in combination with a phosphoric acid etchant. Previously, we showed that $0.5 \%$ BAC concentration can effectively inhibit soluble MMP-2, MMP-8, or MMP-9, and to some extent matrix-bound MMPs, even though the effect was not as strong with matrix-bound dentin MMPs as with soluble recombinant MMPs [81]. Later, Sabatini et al. showed that BAC-containing adhesive blends can increase the durability of resin-dentin bonds, showing only $9 \%$ reductions, compared to over $30 \%$ reduction in controls [83]. Several other polymerizable quaternary ammonium compounds have been tested for their ability to inhibit dentin matrix-bound MMPs [71•, 82]. Among them, 12methacryloyloxydodecylpyridinium bromide (MDPB) was found to be a good MMP and cathepsin inhibitor [71 , 81-83]. MDPB has been in clinical use for years due to its strong anti-bacterial effects [84]. A previous in vivo study also showed more durable bonding with the use of MDPB incorporated bonding agent [85], whereas others showed significant bond strength reduction over time $[86,87]$. The inhibitory effect of MDPB on proteaolytic activity may be lost over time and requires further verification to draw definitive conclusions.

Another approach to reduce the collagen degradation at the adhesive interfaces is to use collagen cross-linking agents. The cross-linking of collagen using synthetic collagen crosslinkers such as glutaraldehyde or carbodiimide, or natural cross-linkers such as proanthocyanidins, has been shown to increase mechanical properties of dentin matrix by enhancing intra- and inter-molecular cross-links of collagen [88-90]. Moreover, they have been reported to improve the degradation resistance of collagen matrices to dentinal proteases [91, 94]. The cross-linker application was suggested to inactivate the active sites of dentin proteases by reducing the molecular mobility or by changing negatively charged ionized carboxyl groups into positive charged amides [91-94]. Both the low cytotoxicity of natural cross-linkers and their proven efficiency to the mechanical properties of the dentin matrix make these agents promising for clinical applications. Although the published results are very promising, the disadvantage is that some proanthocyanidins are dark colored, and not esthetic and, similar to CHX, their application requires and extra application step.

\section{Strategies to Reduce the Hydrolytic Degradation of Adhesives}

Since hydrolytic degradation of the adhesives is the other challenge for the durability of resin-dentin bonds [20], the use of ethanol to eliminate the excess water from the bonded interface has been proposed [95]. In this technique, chemical dehydration of demineralized dentin matrices with $100 \%$ ethanol pretreatment is used to increase the infiltration of resin monomers into dentin and to avoid phase separation of the 
monomers [20, 24, 96, 97]. Moreover, when water is eliminated from the hybrid layer, the hydrophilic resin monomers can be substituted with more hydrophobic resin mixtures [20]. This results in a homogenously hydrophobic monomer-impregnated hybrid layer [96, 97], and a decrease in the water sorption and plasticization of the resin component of the hybrid layer [27, 39]. Additionally, a previous report showed the inhibition of both rh-MMPs and also matrix-bound MMPs with increasing alcohol doses. The authors speculated that the inhibitory effect of ethanol is based on forming a coordinate covalence bond between the catalytic zinc and the oxygen atom of the hydroxyl group of the alcohol [98].

However, if not properly evaporated, the remaining ethanol at the adhesive layers can decrease the polymerization of the resins, thereby resulting in the reduction in physicomechanical properties [99]. Despite the promising results at the laboratory studies, a recent study comparing the laboratory setting and in vivo test setting showed a $31 \%$ lower bond strength at ethanol wet bonding groups [100]. This result suggest that even though ethanol wet bonding approach is promising, the technique sensitivity of this approach challenges its clinical use and the results obtained in laboratory studies may not be a good indicative for clinical performance.

\section{Summary}

The longevity of adhesive restorations depends on many factors including the properties of adhesive resins, and the successful preservation of demineralized collagen fibrils at the adhesive interface. The goal in research on how to improve the durability of resin-dentin bonds is to extend the durability of these bonds to be similar to that of resinenamel bonds (i.e., 20-30 years). This will require the development of resin composites that are more stable in water, as well as dimethacrylates that have better water solubility. Improvements in comonomer infiltration are also needed. Clinicians may have to abandon the use of simplified adhesives and return to multistep procedures with longer infiltration and solvent evaporation steps. If the next 60 years is as exciting as the past 60 years, we will eventually learn how to create perfect resin-dentin bonds that last 30 years.

\begin{abstract}
Acknowledgments The research was supported by grant \#8126472 from the Academy of Finland to AT-M (PI), EVO funding of Turku University Hospital to AT-M (PI). The authors do not have a financial interest in products, equipment, and companies cited in the manuscript.
\end{abstract}

\section{Compliance with Ethical Standards}

Conflict of Interest The authors have nothing to disclose.
Human and Animal Rights and Informed Consent This article does not contain any studies with human or animal subjects performed by any of the authors.

\section{References}

Papers of particular interest, published recently, have been highlighted as:

- Of importance

•. Of major importance

1. Degrange M, Roulet JF. Minimally invasive restorations with bonding. Chicago: Quintessence Publishing; 1997.

2. Ferracane J, Fisher J, Eisele JL, et al. Ensuring the global availability of high-quality dental restorative materials. Adv Dent Res. 2013;25:41-5.

3. De Munck J, Van Landuyt K, Peumans M, et al. A critical review of the durability of adhesion to tooth tissue: methods and results. J Dent Res. 2005;84:118-32.

4. Lucarotti PS, Holder RL, Burke FJ. Outcome of direct restorations placed within the general dental services in England and Wales (Part 1): variation by type of restoration and re-intervention. $\mathrm{J}$ Dent. 2005;33:805-15.

5. NIDCR Strategic Plan 2009-2013 http://www.nidcr.nih.gov/ Research/ResearchPriorities/StrategicPlan/.

6. Abt E. The risk of failure is higher for composites than for amalgam restorations. J Evid Based Dent Prac. 2008;8:83-4.

7. Simecek JW, Diefenderfer KE, Cohen ME. An evaluation of replacement rates for posterior resin-based composites and amalgam restorations in U.S. Navy and Marine Corp recruits. J Am Dent Assoc. 2009;140:200-9.

8. Gaengler P, Hoyer I, Montag R, et al. Micromorphological evaluation of posterior composite restorations: a 10 year report. J Oral Rehab. 2004;31:991-1000.

9. Opdam NJ, van de Sande FH, Bronkhorst E, et al. Longevity of posterior composite restorations: a systematic review and metaanalysis. J Dent Res. 2014;93:943-9.

10. Bertassoni LE, Habelitz S, Kinney JH, et al. Biomechanical perspective on the remineralization of dentin. Caries Res. 2009;43: 70-7.

11. Ten NA. Cate's oral histology: development, structure, and function. 8th ed. St. Louis: Mosby; 2012.

12. Buonocore MG. A simple method of increasing the adhesion of acrylic filling materials to enamel surfaces. J Dent Res. 1955;34: 849-53.

13. Legler LR, Retief DH, Bradley EL. Effects of phosphoric acid concentration and etch duration on enamel depth of etch: an in vitro study. Am J Orthod Dentofacial Orthop. 1990;98:154-60.

14. Triolo Jr PT, Swift Jr EJ, Mudgil A, et al. Effects of etching time on enamel bond strengths. Am J Dent. 1993;6:302-4.

15. Gwinnett AJ, Matsui A. A study of enamel adhesives. The physical relationship between enamel and adhesive. Arch Oral Biol. 1967; 12:1615-20.

16. Van Meerbeek B, De Munck J, Yoshida Y, et al. Buonocore memorial lecture. Adhesion to enamel and dentin: current status and future challenges. Oper Dent. 2003;28:215-35.

17. Beier US, Kapferer I, Burtscher D, et al. Clinical performance of porcelain laminate veneers for up to 20 years. Int J Prosthodont. 2012;25:79-85.

18. De Munck J, Van Meerbeek B, Yoshida Y, et al. Four-year water degradation of total-etch adhesives bonded to dentin. J Dent Res. 2003;82:136-40. 
19. Butler WT. Dentin collagen: chemical structure and role in mineralization. In: Linde A, editor. Dentin and dentinogenesis, vol. II. Boca Raton: CRC Press; 1984. p. 40.

20. Pashley DH, Tay FR, Breschi L, et al. State of the art etch-andrinse adhesives. Dent Mater. 2011;27:1-16.

21. Nakabayashi N, Kojima K, Masuhara E. The promotion of adhesion by the infiltration of monomers into tooth substances. J Biomed Mater Res. 1982;16:265-73.

22. Pashley DH, Agee KA, Wataha JC, et al. Viscoelastic properties of demineralized dentin matrix. Dent Mater. 2003;19:700-6.

23. Hashimoto M, Ohno H, Kaga M, et al. In vivo degradation of resin-dentin bonds in humans over 1 to 3 years. J Dent Res. 2000;79:1385-91.

24. Tjäderhane L, Nascimento FD, Breschi L, et al. Strategies to prevent hydrolytic degradation of the hybrid layer-a review. Dent Mater. 2013;29:999-1011.

25. Hebling J, Pashley DH, Tjäderhane L, et al. Chlorhexidine arrests subclinical degradation of dentin hybrid layers in vivo. J Dent Res. 2005;84:741-6.

26. Hashimoto M, Ohno H, Kaga M, et al. Resin-tooth adhesive interfaces after long-term function. Am J Dent. 2001;14:211-5.

27. Ferracane JL. Hygroscopic and hydrolytic effects in dental polymer networks. Dent Mater. 2006;22:211-22.

28. Bowen RL, Eick JD, Henderson DA, et al. Smear layer: removal and bonding considerations. Oper Dent Suppl. 1984;3:30-4.

29. Ermis RB, De Munck J, Cardoso MV, et al. Bond strength of selfetch adhesives to dentin prepared with three different diamond burs. Dent Mater. 2008;24:978-85.

30. Van Meerbeek B, Van Landuyt K, De Munck J, et al. Technique sensitivity of contemporary adhesives. Dent Mater J. 2005;24:1-13.

31. Wang Y, Spencer P. Hybridization efficiency of the adhesive/ dentin interface with wet bonding. J Dent Res. 2003;82:141-5.

32. Hashimoto M, Tay FR, Ohno H, et al. SEM and TEM analysis of water degradation of human dentinal collagen. J Biomed Mater Res B Appl Biomater. 2003;66:287-98.

33. Peumans M, De Munck J, Mine A, et al. Clinical effectiveness of contemporary adhesives for the restoration of non-carious cervical lesions. A systematic review. Dent Mater. 2014;30:1089-103.

34. Moszner N, Salz U, Zimmermann J. Chemical aspects of selfetching enameldentin adhesives: a systematic review. Dent Mater. 2005;21:895-910.

35. Mine A, De Munck J, Cardoso MV, et al. Dentin-smear remains at self-etch adhesive interface. Dent Mater. 2014;30:1147-53.

36. Kanca 3rd J. Resin bonding to wet substrate. 1. bonding to dentin. Quintessence Int. 1992;23:39-41.

37. Van Landuyt KL, Snauwaert J, De Munck J, et al. Systematic review of the chemical composition of contemporary dental adhesives. Biomaterials. 2007;28:3757-85.

38. Spencer P, Wang Y. Adhesive phase separation at the dentin interface under wet bonding conditions. J Biomed Mater Res. 2002;62: 447-56.

39. Ito S, Hashimoto M, Wadgaonkar B, et al. Effects of resin hydrophilicity on water sorption and changes in modulus of elasticity. Biomaterials. 2005;26:6449-59.

40. Ikeda T, De Munck J, Shirai K, et al. Effect of evaporation of primer components on ultimate tensile stregth of primeradhesive mixtures. Dent Mater. 2005;21:1051-8.

41. Yiu CK, King NM, Carrilho MR, et al. Effect of resin hydrophilicity and temperature on water sorption of dental adhesive resins. Biomaterials. 2005;26:6863-72.

42. Ye Q, Spencer P, Wang Y, et al. Relationship of solvent to the photopolymerization process, properties, and structure in model dentin adhesives. J Biomed Mater Res a. 2007;80:342-50.
43. Tay FR, Frankenberger R, Krejci I, et al. Single-bottle adhesives behave as permeable membranes after polymerization. I. In vivo evidence. J Dent. 2004;32:611-21.

44. Tay FR, Pashley DH. Water treeing- a potential mechanism for degradation of dentin adhesives. Am J Dent. 2003;16:6-12.

45. Dayan D, Binderman I, Mechanic GL. A preliminary study of activation of collagenase in carious human dentin matrix. Arch Oral Biol. 1983;28:185-7.

46. Tjäderhane L, Larjava $\mathrm{H}$, Sorsa $\mathrm{T}$, et al. The activation and function of host derived matrix metalloproteinases in dentin matrix breakdown in caries lesions. J Dent Res. 1998;77:1622-9.

47. Armstrong SR, Vargas MA, Chung I, et al. Resin-dentin interfacial ultrastructure and microtensile dentin bond strength after fiveyear water storage. Oper Dent. 2004;29:705-12.

48. Pashley DH, Tay FR, Yiu C, et al. Collagen degradation by hostderived enzymes during aging. J Dent Res. 2004;83:216-21.

49. Breschi L, Prati C, Gobbi P, et al. Immunohistochemical analysis of collagenfibrils within the hybrid layer:a FEISEM STUDY. Oper Dent. 2004;29:538-46.

50. Mazzoni A, Nascimento FD, Carrilho M, et al. MMP activity in the hybrid layer detected with in situ zymography. J Dent Res. 2012;91:467-72.

51. Carrilho MR, Geraldeli S, Tay F, et al. In vivo preservation of the hybrid layer by chlorhexidine. J Dent Res. 2007;86:529-33.

52. Liu Y, Tjäderhane L, Breschi L, et al. Limitations in bonding to dentin and experimental strategies to prevent bond degradation. J Dent Res. 2011;90:953-68.

53. Tjäderhane L, Nascimento FD, Breschi L, et al. Optimizing dentin bond durability: control of collagen degradation by matrix metalloproteinases and cysteine cathepsins. Dent Mater. 2013;29:116-35. This review article provides a detailded overview of the endogenous proteases and dentin degradation mechanisms.

54. Perdigão J, Reis A, Loguercio AD. Dentin adhesion and MMPs: a comprehensive review. J Esthet Restor Dent. 2013;25:219-41.

55. Palosaari H, Pennington CJ, Larmas M, et al. Expression profile of matrix metalloproteinases (MMPs) and tissue inhibitors of MMPs in mature human odontoblasts and pulp tissue. Eur J Oral Sci. 2003;111:117-27.

56. Tersariol IL, Geraldeli S, Minciotti CL, et al. Cysteine cathepsins in human dentin-pulp complex. J Endod. 2010;36:475-81.

57. Visse R, Nagase H. Matrix metalloproteinases and tissue inhibitors of metalloproteinases: structure, function, and biochemistry. Circ Res. 2003;92:827-39.

58.• Vidal CM, Tjäderhane L, Scaffa PM, et al. Abundance of MMPs and cysteine cathepsins in caries-affected dentin. J Dent Res. 2014;93:269-74. This study shows the increased activity of MMPs and also cysteine cathepsins in caries-affected dentin.

59. Buzalaf MA, Kato MT, Hannas AR. The role of matrix metalloproteinases in dental erosion. Adv Dent Res. 2012;24:72-6.

60. Palosaari H, Wahlgren J, Larmas M, et al. The expression of MMP-8 in human odontoblasts and dental pulp cells is downregulated by TGF-beta1. J Dent Res. 2000;79:77-84.

61. Martin-De Las Heras S, Valenzuela A, Overall CM. The matrix metalloproteinase gelatinase A in human dentine. Arch Oral Biol. 2000;45:757-65.

62. Mazzoni A, Mannello F, Tay FR, et al. Zymographic analysis and characterization of MMP-2 and -9 forms in human sound dentin. J Dent Res. 2007;86:436-40.

63. Boukpessi T, Menashi S, Camoin L, et al. The effect of stromelysin-1 (MMP-3) on non-collagenous extracellular matrix proteins of demineralized dentin and the adhesive properties of restorative resins. Biomaterials. 2008;29:4367-73.

64. Sulkala M, Tervahartiala T, Sorsa T, et al. Matrix metalloproteinase 8 (MMP-8) is the major collagenase in human dentin. Arch Oral Biol. 2007;52:121-7. 
65. Perumal S, Antipova O, Orgel JP, et al. Collagen fibril architecture, domain organization, and triple-helical conformation govern its proteolysis. Proc Natl Acad Sci U S A. 2008;26(105):2824-9.

66. Toledano M, Nieto-Aguilar R, Osorio R, et al. Differential expression of matrix metalloproteinase-2 in human coronal and radicular sound and carious dentine. J Dent. 2010;38:635-40.

67. Nishitani Y, Yoshiyama M, Wadgaonkar B, et al. Activation of gelatinolytic/collagenolytic activity in dentin by self-etching adhesives. Eur J Oral Sci. 2006;114:160-6.

68. Tezvergil-Mutluay A, Mutluay M, Seseogullari-Dirihan R, et al. Effect of phosphoric acid on the degradation of human dentin matrix. J Dent Res. 2013;92:87-91.

69. Nascimento FD, Minciotti CL, Geraldeli S, et al. Cysteine cathepsins in human carious dentin. J Dent Res. 2011;90:506-11.

70. Garnero P, Ferreras M, Karsdal MA, et al. The type I collagen fragments ICTP and CTX reveal distinct enzymatic pathways of bone collagen degradation. J Bone Miner Res. 2003;18:859-67.

71. Tezvergil-Mutluay A, Agee KA, Mazzoni A, et al. Can quaternary ammonium methacrylates inhibit MMPs and cathepsins? Dent Mater. 2015;31:e25-32. This study demonstrates that among the cathepsins only Cat-K is able to produce CTX in demineralzied dentin matrices. Both studies evaluate a wide range of inhibitors to identify their effect on MMP-mediated or Cathepsin-mediated degradation.

72. Gendron R, Grenier D, Sorsa T, et al. Inhibition of the activities of matrix metalloproteinases 2,8 and 9 by chlorhexidine. Clin Diagn Lab Immunol. 1999;6(3):437-9.

73. Scaffa PM, Vidal CM, Barros N, et al. Chlorhexidine inhibits the activity of dental cysteine cathepsins. J Dent Res. 2012;91:420-5.

74. Tezvergil-Mutluay A, Tjäderhane L. Current concepts in dental adhesion. Tandlaegebladet. 2011;115:36-42.

75. Loguercio AD, Stanislawczuk R, Polli LG, et al. Influence of chlorhexidine digluconate concentration and application time on resin-dentin bond strength durability. Eur J Oral Sci. 2009;117: 587-96.

76. Brackett MG, Tay FR, Brackett WW, et al. In vivo chlorhexidine stabilization of hybrid layers of acetone-based dental adhesive. Oper Dent. 2009;34:379-83.

77. Ricci HA, Sanabe ME, de Souza Costa CA, et al. Chlorhexidine increases the longevity of in vivo resin-dentin bonds. Eur J Oral Sci. 2010;118:411-6.

78. Kim J, Uchiyama T, Carrilho M, et al. Chlorhexidine binding to mineralized versus demineralized dentin powder. Dent Mater. 2010;26:771-8.

79. Sadek FT, Braga RR, Muench A, et al. Ethanol-wet bonding challenges current anti-degradation strategy. J Dent Res. 2010;89: 1499-504.

80. Tezvergil-Mutluay, Agee K, Mutluay MM, et al. Use of chlorhexidinemethacrylate to inhibit dentin MMPs. J Dent Res 2010: Issue 89B Abstract \#: 1369.

81. Tezvergil-Mutluay A, Mutluay MM, Gu LS, et al. The anti-MMP activity of benzalkonium chloride. J Dent. 2011;39:57-64.

82. Tezvergil-Mutluay A, Agee KA, Uchiyama T, et al. The inhibitory effects of quaternary ammonium methacrylates on soluble and matrix-bound MMPs. J Dent Res. 2011;90:535-40.
83. Sabatini C, Ortiz PA, Pashley DH, et al. Preservation of resindentin interfaces treated with benzalkonium chloride adhesive blends. Eur J Oral Sci. 2015;123:108-15.

84. Imazato S. Bioactive restorative materials with antibacterial effects: new dimension of innovation in restorative dentistry. Den Mater J. 2009;28:11-9.

85. Donmez N, Belli S, Pashley DH, et al. Ultrastructural correlates of in vivo/ in vitro bond degradation in self-etch adhesives. J Dent Res. 2005;84:355-59.

86. De Munck J, Mine A, Van den Steen PE, et al. Enzymatic degradation of adhesive-resin interfaces produced by mild self-etch adhesives. Eur J Oral Sci. 2010;118:494-501.

87. De Munck J, Mine A, Vivan Cardoso M, et al. Effect of dentin location and longterm water storage on bonding effectiveness of dentin adhesives. Dent Mater J. 2011;30:7-13.

88. Bedran-Russo AK, Pereira PN, Duarte WR, et al. Application of crosslinkers to dentin collagen enhances the ultimate tensile strength. J Biomed Mater Res B Appl Biomater. 2007;80:268-72.

89. Bedran-Russo AK, Pashley DH, Agee K, et al. Changes in stiffness of demineralized dentin following application of collagen crosslinkers. J Biomed Mater Res B Appl Biomater. 2008;86B: $330-4$.

90. Al-Ammar A, Drummond JL, Bedran-Russo AK. The use of collagen crosslinking agents to enhance dentin bond strength. J Biomed Mater Res B Appl Biomater. 2009;91:419-24.

91. Tezvergil-Mutluay A, Mutluay MM, Agee KA, et al. Carbodiimide cross-linking inactivates soluble and matrixbound MMPs, in vitro. J Dent Res. 2012;91:192-6.

92. Mazzoni A, Angeloni V, Apolonio FM, et al. Effect of carbodiimide (EDC) on the bond stability of etch-and-rinse adhesive systems. Dent Mater. 2013;29:1040-7.

93. Cova A, Breschi L, Nato F, et al. Effect of UVA-activated riboflavin on dentin bonding. J Dent Res. 2011;90:1439-45.

94. Seseogullari-Dirihan R, Mutluay MM, Vallittu P, et al. Effect of pretreatment with collagen crosslinkers on dentin protease activity. Dent Mater. 2015;31:941-47.

95. Pashley DH, Tay FR, Carvalho RM, et al. From dry bonding to water-wet bonding to ethanol-wet bonding. A review of the interactions between dentin matrix and solvated resins using a macromodel of the hybrid layer. Am J Dent. 2007;20:7-20.

96. Sauro S, Watson TF, Mannocci F, et al. Two-photon laser confocal microscopy of micropermeability of resin-dentin bonds made with water or ethanol wet bonding. J Biomed Mater Res. 2009;90:327-37.

97. Shin TP, Yao X, Huenergardt R, et al. Morphological and chemical characterization of bonding hydrophobic adhesive to dentin using ethanol wet bonding technique. Dent Mater. 2009;25:1050-57.

98. Tezvergil-Mutluay A, Agee KA, Hoshika T, et al. Inhibition of MMPs by alcohols. Dent Mater. 2011;27:926-33.

99. Cadenaro M, Breschi L, Rueggeberg FA, et al. Effect of adhesive hydrophilicity and curing time on the permeability of resins bonded to water vs. ethanol-saturated acid-etched dentin. Dent Mater. 2009;25:39-47.

100. Kuhn E, Farhat P, Teitelbaum AP, et al. Ethanol-wet bonding technique: clinical versus laboratory findings. Dent Mater. 2015;31:1030-7. 